\title{
Tenotomia artroscópica do músculo bíceps braquial em cadáveres de cães
}

\author{
Arthroscopic brachial biceps tenotomy in dog's cadavers
}

\author{
Angelica Cecilia Tatarunas ${ }^{1}$ Julia Maria Matera ${ }^{2}$
}

\section{RESUMO}

O objetivo do trabalho foi a avaliação experimental da tenotomia artroscópica do tendão do músculo bíceps braquial com o uso de agulha hipodérmica, de lâmina de bisturi $n^{\circ} 15$ e de bisturi de radiofreqüência em cadáveres de cães. Os portais artroscópico e instrumental foram confeccionados caudal e cranial ao processo do acrômio, respectivamente, e, se necessário, foi estabelecido um portal instrumental acessório cranial e próximo ao sulco intertubercular. $O$ bisturi de radiofreqüência e o bisturi com lâmina $n^{\circ} 15$ se mostraram superiores quanto ao tempo $e$ qualidade de corte em relação à agulha hipodérmica para a secção do tendão do músculo bíceps braquial. A principal complicação ocorrida durante o procedimento para a secção do tendão foi a quebra da lâmina de bisturi no interior de uma articulação devido à dificuldade de visibilização da transição entre o tubérculo supraglenoidal e o tendão, em conseqüência da presença de hiperplasia de sinóvia no local. Em todos os grupos, houve dificuldade para a secção de uma estrutura semelhante a uma plica ao final do procedimento, a qual não tinha sido ainda descrita. Concluiu-se que os portais lateral e caudal para o artroscópio e lateral e cranial para o instrumental foram satisfatórios quando a lâmina de bisturi $n^{\circ} 15$ ou o bisturi de radiofreqüência foram utilizados para a secção proximal do tendão do músculo bíceps braquial.

Palavras-chave: artroscopia, tendão do músculo bíceps braquial, articulação do ombro, canino.

\section{ABSTRACT}

The purpose of this study was the experimental evaluation of the arthroscopic brachial biceps tenotomy in dogs cadavers using needle, $n^{\circ}$ ㅇ 15 scalpel blade and radiofrequency scalpel. The arthroscopic and instrumental portals were performed caudal and cranial to the acromial process, respectively. When necessary, an accessory instrumental portal, cranial and near the intertubercular groove was used too. Better sectional time and quality of the seccioned edges were showed by the radiofrequency scalpel and the $n^{\circ} 15$ scalpel blade than the hypodermic needle. The break of the blade scalpel inside one joint was the main complication that occurred during the section tendon procedure. It was difficult to see the transition between the supraglenoidal tubercle and the tendon due the presence of sinovial hyperplasia. In this research there was a dificulty to cut a structure as a plica in the end of the procedure in all groups, which have not been described before. In conclusion the lateral and caudal arthroscopic and lateral and cranial instrumental portals were satisfactory for the arthroscopic brachial biceps tenotomy when the $n^{\circ} 15$ scalpel blade and radiofrequency scalpel were used.

Key words: arthroscopy, brachial biceps tendon, shoulder joint, canine.

\section{INTRODUÇÃO}

As afecções da articulação escápulo-umeral (AEU) são causas freqüentes de claudicação do membro torácico no cão (PIERMATTEI \& FLO, 1997) e as afecções do tendão do músculo bíceps braquial (TMBB) constituem importante causa (LINCOLN \& POTTER, 1984; STOBIE et al., 1995; BARDET, 1999; BARDET, 2002; BEALE et al., 2003). Dentre as lesões que acometem o TMBB, citam-se ruptura parcial ou completa, avulsão do tubérculo supraglenoidal, tendinite, tendão bipartido, deslocamento e tenosinovite (GORING et al., 1984; LAHUE et al., 1986; MUIR et al., 1992; MUIR \& JOHNSON, 1994; STOBIE et al., 1995; BARDET, 1999; JOHNSON \& HULSE, 2002; INNES \& BROWN, 2004).

O diagnóstico das alterações do TMBB pode ser difícil (BARDET, 1999), sendo que a artrografia

\footnotetext{
${ }^{1}$ Departamento de Cirurgia da Faculdade de Medicina Veterinária e Zootecnia (FMVZ), Universidade de São Paulo (USP),0 Av. Dr Orlando Marques de Paiva, 87, Cidade Universitária, 05508-900, São Paulo, SP. Email: angelvet@usp.br. Autor para correspondência. ${ }^{2}$ Departamento de Cirurgia da FMVZ, USP. Email: materajm@usp.br.
} 
de contraste positivo (BARTHEZ \& MORGAN, 1993) e a ultra-sonografia (KRAMER et al., 2001), geralmente indicadas como exames auxiliares, nem sempre são elucidativas (RIVERS et al., 1992). A artroscopia, classicamente utilizada para diagnosticar e tratar as afecções da AEU no homem, vem ganhando importância neste contexto também para a espécie canina (PERSON, 1986; VAN RYSSEN et al., 1993; MCCARTHY, 1999; MARTINI et al. 2002; VANRYSSEN et al., 2003; BEALE et al., 2003).

O tratamento cirúrgico de tenosinovite e de ruptura parcial do TMBB no cão consistem classicamente na secção e tenodese do tendão, através de artrotomia medial da AEU, com resultados variados (LINCOLN \& POTTER, 1984; PIERMATTEI \& FLO, 1997; INNES \& BROWN, 2004). A tenotomia via artroscopia do TMBB vem sendo empregada alternativamente ao tratamento cirúrgico convencional em cães e os resultados relatados têm sido satisfatórios (WALL \& TAYLOR, 2002; BEALE et al., 2003). Tal procedimento cessa o movimento do tendão através do sulco intertubercular e acredita-se que ocorra a formação de aderências do tendão seccionado junto ao úmero proximal e, conseqüentemente, uma tenodese natural (WALL \& TAYLOR, 2002).

Dado o crescente interesse por este tópico, o presente trabalho visa a descrever a técnica da tenotomia proximal via artroscopia do TMBB, e avaliar a sua realização com o uso de agulha hipodérmica, lâmina de bisturi nำ 15 e radiofreqüência, em cadáveres de cães.

\section{MATERIAL E MÉTODOS}

Foram estudadas 36 articulações escápuloumerais (AEUs) de 18 cães que vieram a óbito no Hospital Veterinário da Faculdade de Medicina Veterinária e Zootecnia da Universidade de São Paulo. $\mathrm{O}$ instrumental utilizado para a artroscopia consistiu de artroscópio ${ }^{a}$ de $2,7 \mathrm{~mm}$, comprimento de trabalho $18 \mathrm{~cm}$ e ângulo de lente $30^{\circ}$, cânula de alto fluxo $4 \mathrm{~mm}$, trocarte agudo ${ }^{\mathrm{a}}$ e rombo ${ }^{\mathrm{a}}$ e sonda ${ }^{\mathrm{a}}$. A fonte de luz fria é obtida com lâmpada de xenônio $175 \mathrm{~W}$, cabo de fibra óptica $3 \mathrm{~mm}$ largura e $250 \mathrm{~cm}$ comprimento, monitor colorido, unidade de controle de câmera ${ }^{a}$ e cabeça da câmera ${ }^{\mathrm{a}} \mathrm{e}$ instrumental cirúrgico. A documentação do exame artroscópico foi realizada através de videoimpressora $^{\mathrm{b}}$ e/ou filmagem ${ }^{\mathrm{c}}$.

O bisturi de radiofreqüência bipolar ${ }^{d}$ consistiu de caneta, placa, prolongador e lâmina.
Técnica cirúrgica do exame artroscópico

Os membros torácicos foram tricotomizados e os cadáveres colocados em decúbito lateral, com o membro a ser abordado para cima e a AEU em posição neutra $\left(160^{\circ}\right)$.

Após a identificação dos pontos anatômicos de referência da articulação (acrômio, tuberosidade maior do úmero e tendão do músculo infraespinhoso), realizou-se artrocentese com agulha hipodérmica 30x8 na superfície lateral da articulação, entre o processo do acrômio e a cabeça do úmero. Uma seringa de $20 \mathrm{~mL}$ com solução fisiológica foi acoplada à agulha e o líquido infundido até que se observasse resistência no êmbolo da seringa.

O portal artroscópico foi confeccionado em posição lateral e caudal ao processo do acrômio (BEALE et al., 2003). Para tal, foi feita incisão cutânea de cerca de $1,0 \mathrm{~cm}$ de comprimento, com lâmina de bisturi no 15 , caudal ao processo do acrômio. Deu-se preferência à utilização do trocarte rombo com a cânula para perfurar a cápsula articular e adentrar a articulação. Durante esta manobra, realizou-se concomitante tração pela extremidade do membro. $\mathrm{Na}$ sequiência, o trocarte foi substituído pelo artroscópio. Um equipo para soluções parentais foi acoplado a um frasco de solução fisiológica foi conectado à cânula do artroscópio, servindo de via de influxo por gravidade. Inicialmente, uma agulha hipodérmica $30 \times 8$ foi utilizada como portal de drenagem, em posição crânio medial.

As AEUs foram divididas em três grupos: grupo A, composto de 12 AEUs, nas quais foi realizada a tenotomia proximal do TMBB com agulha hipodérmica; grupo $\mathrm{B}$, constituído de 12 AEUs, nas quais procedeu-se à tenotomia proximal do TMBB com lâmina de bisturi; e grupo C, formado por 8 AEUs, nas quais utilizou-se o bisturi de radiofrequiência para a realização da tenotomia proximal do TMBB.

Avaliou-se o tempo, a localização e o aspecto das bordas da incisão (regulares ou irregulares, transverso ou oblíquo). O tempo foi graduado como rápido ( $<1$ minuto), intermediário ( 2 a 5 minutos) ou tardio ( $>5$ minutos) e compreendeu do momento em que o instrumento de corte foi posicionado junto ao terço proximal do TMBB até a sua completa secção. Dificuldades e complicações transcorridas durante o procedimento foram registradas.

O portal instrumental foi confeccionado pela técnica de triangulação em posição lateral e cranial ao processo do acrômio (BEALE et al., 2003). Na impossibilidade ou dificuldade da realização do procedimento cirúrgico pela técnica artroscópica proposta, confeccionou-se um segundo portal instrumental acessório cranial à articulação, junto ao sulco intertubercular (Figura 1) (PERSON, 1986; HOLSWORTH et al. 2002). 


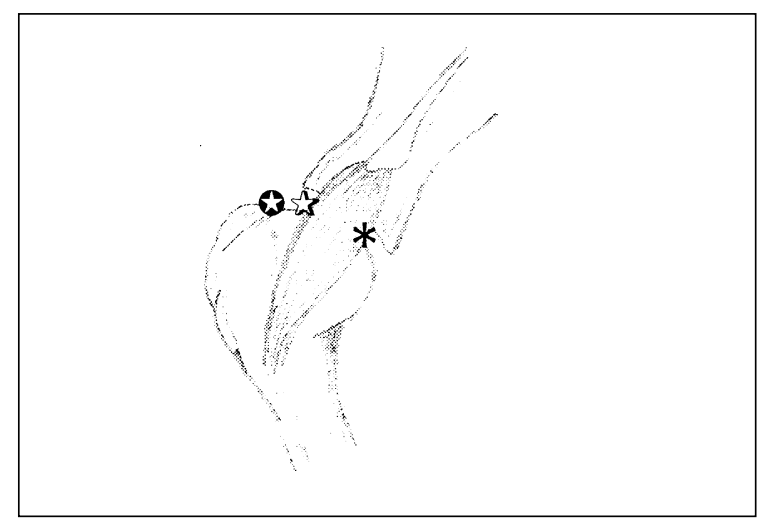

Figura 1 - Diagrama dos portais artroscópio - lateral e caudal ao processo do acrômio (*), instrumental - lateral e cranial ao processo do acrômio ( $\boldsymbol{\star}$ ) e instrumental acessório - cranial, junto ao sulco intertubercular (*)

Grupo A-Técnica cirúrgica

Uma agulha hipodérmica 40×12 foi introduzida em posição cranial ao processo do acrômio. Após a sua localização pelo artroscópio, avaliou-se a sua posição quanto à possibilidade de realização do procedimento proposto. Procedeu-se então à secção proximal do tendão (Figura 2).

Grupo B - Técnica Cirúrgica

A confecção do portal instrumental foi estabelecida pela técnica da triangulação. Para isto, introduziu-se inicialmente uma agulha hipodérmica 40x12 em posição cranial ao processo do acrômio. Após a sua localização pelo artroscópio, fez-se incisão de pele de $1,0 \mathrm{~cm}$ junto ao orifício de entrada da agulha. $\mathrm{Na}$ seqüência, o bisturi foi introduzido através desta incisão, com o corte da lâmina voltado para cima. A perfuração da cápsula sinovial articular foi monitorada pelo artroscópio. Após adentrar a articulação, iniciouse a secção do tendão no terço proximal junto ao tubérculo supraglenoidal com lâmina de bisturi nํㅜㄴ (Figura 2).

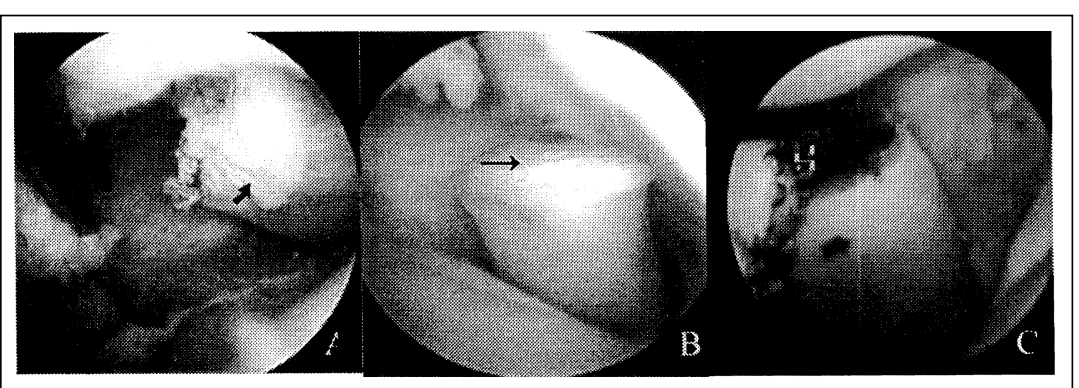

Figura 2 - Articulação escápulo-umeral em cadáver de cão. Em A, observa-se segmento distal do TMBB após a secção com agulha hipodérmica ( $\rtimes$ ); em B, segmento distal do TMBB após secção com lamina de bisturi $(\rightarrow)$; em $\mathrm{C}$, segmento distal do TMBB após secção com bisturi de radiofreqüência $(\vec{l})$

\section{Grupo C - Técnica cirúrgica}

Determinou-se a localização do portal instrumental pela técnica da triangulação, semelhante à técnica descrita para a tenotomia do TMBB com o uso de bisturi. O bisturi de radiofreqüência foi introduzido através do portal instrumental e promoveuse a secção do tendão junto ao tubérculo supraglenoidal (Figura 2).

\section{RESULTADOS}

No grupo A, o peso dos cadáveres foi de 12 a $50 \mathrm{~kg}$ (média $26,7 \mathrm{~kg}$ ). A quantidade de líquido inicialmente infundida na articulação foi proporcional ao porte do animal e variou de 8 a $25 \mathrm{~mL}$ (média 14,6mL). O tempo de secção foi considerado rápido em um $(8,4 \%)$ cadáver (40 segundos), intermediário em quatro $(33,4 \%)$ (média 2 minutos e 25 segundos, sendo o tempo máximo 3 minutos) e tardio em sete $(58,4 \%$ ) (média 10 minutos, sendo o tempo maximo 15 minutos). A secção foi realizada na região proximal em seis $(50 \%)$ tendões e na região médio proximal em outros seis $(50 \%)$; mostrouse de forma oblíqua em três $(25 \%)$ e transversal em nove $(75 \%)$. Os bordos apresentaram-se irregulares após a tenotomia em outros seis (50\%) tendões. Lesão iatrogênica de cartilagem ocorreu na superfície cranial da cabeça do úmero em três $(25 \%)$ articulações e no tendão subescapular em dois $(16,7 \%)$. Houve a necessidade da confecção do portal instrumental acessório em cinco $(41,7 \%)$ articulações. A agulha hipodérmica utilizada como instrumento de corte mostrou-se curta para o objetivo proposto em quatro $(33,4 \%)$ procedimentos e entortou em quatro $(33,4 \%)$, necessitando ser substituída várias vezes em cinco $(41,7 \%)$ articulações. Em uma articulação, houve dificuldade no seu adequado reposicionamento quando da sua substituição. Outras intercorrências do procedimento consistiram da presença de hiperplasia de sinóvia em uma articulação, dificultando a visualização do local exato da tenotomia, e a secção da membrana sinovial que se dispõe semelhantemente a uma plica, em posição cranial ao TMBB, coligando a cápsula articular cranial com a bainha do tendão do bíceps.

No grupo B, o peso dos cadáveres foi de 12 a 30 kg (média 20,4kg). A quantidade de líquido infundida durante a artrocentese inicial variou de 
5 a $20 \mathrm{~mL}$ (média $11,7 \mathrm{~mL}$ ). O tempo decorrido para a secção do tendão foi de até um minuto em onze $(91,7 \%)$ (média 17 segundos, sendo o tempo máximo 30 segundos) articulações e maior do que 5 minutos em uma $(8,4 \%)$ (1 minuto e 30 segundos). As bordas mostraram-se regulares e a secção foi transversal em onze $(91,7 \%)$ tendões, sempre na região proximal. Lesão iatrogênica de cartilagem ocorreu em três (25\%) articulações (superfície da cabeça do úmero e cavidade glenóide) e perfuração da cápsula articular cranial em uma $(8,4 \%)$. Em uma articulação, a tentativa inicial de secção foi muito proximal, sobre o tubérculo supraglenoidal, havendo quebra da lâmina de bisturi no interior da articulação. A remoção desta foi realizada via artroscopia, com auxílio de pinça de apreensão. Dificuldades durante o procedimento consistiram na presença de hiperplasia de sinóvia em uma articulação próxima ao tubérculo supraglenoidal, dificultando a visualização e a liberação da membrana sinovial que fica aderida a bainha do tendão, em sua região cranial, em três $(25 \%)$ articulações.

No grupo C, o peso dos cadáveres foi de 18 a $35 \mathrm{~kg}$ (média 23,1 kg). A quantidade de líquido infundida inicialmente na articulação variou de 5 a $20 \mathrm{~mL}$ (média $13,7 \mathrm{~mL})$. O tempo de secção foi curto em todas as articulações (100\%) (média 25 segundos, sendo o tempo máximo 38 segundos), as bordas mostraram-se regulares e foram realizados cortes transversalmente na região proximal do tendão nas 12 articulações estudadas $(100 \%)$. Perfuração da cápsula articular cranial ocorreu em quatro $(33,3 \%)$ articulações e lesão iatrogênica de cartilagem da cavidade glenóide em uma $(8,3 \%)$. Em todas as articulações, as bolhas decorrentes do uso do bisturi de radiofreqüência promoveram obstrução parcial do campo de visão (100\%). Houve dificuldade na secção da membrana sinovial aderida à bainha do tendão com o bisturi de radiofreqüência em quatro $(33,3 \%)$ articulações.

\section{DISCUSSÃO}

A artroscopia da AEU no cão tem potencial de diagnóstico e tratamento (BARDET, 1999; BEALE et al., 2003; VANRYSSEN et al., 2003; INNES \& BROWN, 2004; JOHNSON \& HULSE, 2002). As afecções que acometem o TMBB são a terceira causa de doença da AEU e a ruptura parcial ou total deste tendão, associado ou não à tenosinovite, constitui a sua principal enfermidade (BARDET, 2002). Recentemente, tem-se preconizado a tenotomia via artroscopia do
TMBB para o tratamento de tenosinovite ou ruptura parcial deste tendão (WALL \& TAYLOR, 2002; BEALE et al., 2003). A melhor localização para se realizar a secção é desconhecida. Enquanto alguns autores preconizam a secção junto ao sulco intertubercular (HOLSWORTH et al., 2002), outros o fazem próximo ao tubérculo supraglenoidal (WALL \& TAYLOR, 2002; JOHNSON \& HULSE, 2002; BEALE et al., 2003). Neste trabalho, optou-se pela secção proximal por acreditarse que, clinicamente, uma maior quantidade de tecido tendíneo junto ao sulco intertubercular favorece a ocorrência de aderência, um dos objetivos do procedimento segundo WALL \& TAYLOR (2002).

HOLSWORTH et al. (2002) preconizaram a confecção do portal artroscópico em posição cranial ao processo do acrômio para a secção do TMBB WALL \& TAYLOR (2002), por sua vez, preferiram a sua localização em posição caudal a este. Neste estudo, introduziu-se o artroscópio no interior da articulação através de um portal caudal (WALL \& TAYLOR, 2002), pois, dessa forma, evitou-se proximidade excessiva entre os portais artroscópico e instrumental, o que dificultaria a realização da triangulação.

Segundo MARTINI et al. (2002) e BEALE et al. (2003), o portal instrumental na face lateral da articulação, cranial ao processo do acrômio, permite principalmente a abordagem das estruturas intraarticulares localizadas na região cranial da articulação. Porém, para a realização da secção do TMBB, HOLSWORTH et al. (2002) preferem realizar um portal instrumental ainda mais cranial, junto ao tubérculo supraglenoidal, o qual foi relatado pela primeira vez por PERSON (1986). No presente estudo, confeccionouse o portal instrumental de acordo com MARTINI et al. (2002) e BEALE et al. (2003); porém, quando este se mostrou insatisfatório, foi realizado um portal acessório semelhante ao descrito por PERSON (1986) e HOLSWORTH et al. (2002). A necessidade da criação do portal acessório esteve relacionada principalmente com o instrumento de corte utilizado, não se observando, nesta pesquisa, relação com o peso do animal. Tal portal foi realizado principalmente nas articulações do grupo A $(n=5)$, em que a agulha hipodérmica utilizada foi curta para seccionar o tendão a partir de um portal lateral e cranial ao processo do acrômio. Além deste fato, várias agulhas foram usadas para cada articulação, pois esta perdia o corte facilmente e sofria deformação. A constante substituição das agulhas demandou tempo, promoveu trauma e nem sempre foi possível reposicioná-las no local almejado.

Uma das formas para a confecção do portal instrumental é através de transiluminação intra-articular, 
ou seja, utilização da luz do artroscópio como guia (HOLSWORTH et al., 2002). Apesar de a técnica de triangulação com a agulha ser considerada um procedimento dificultoso (VAN RYSSEN et al., 1993), optou-se pela sua realização, pois crê-se que este implique menor manipulação de equipamento no interior da articulação quando comparado com a transiluminação, minimizando risco de quebra de instrumento e de lesão iatrogênica da cartilagem articular.

Em estudo sobre a secção do TMBB via artroscopia com o uso de lâmina de ponta redonda, shaver, lâmina de bisturi e bisturi de radiofreqüência, HOLSWORTH et al. (2002) concluíram que os dois últimos foram efetivos para a secção. WALL \& TAYLOR (2002), por sua vez, sugerem o uso de bisturi de radiofreqüência ou de bisturi de artroscopia, dando preferência à primeira opção. Os resultados desta pesquisa estão de acordo com os autores supracitados, pois o uso da agulha hipodérmica demandou maior tempo e pior qualidade de secção, enquanto que, a utilização do bisturi com lâmina $\mathrm{n}^{\circ} 15$ e do bisturi de radiofreqüência promoveram o menor tempo e a melhor qualidade de secção nas articulações estudadas.

A ocorrência de lesão iatrogênica durante o procedimento artroscópico é relatada na literatura, sendo a de cartilagem articular a de maior prevalência (BEALE et al., 2003; VAN RYSSEN et al., 2003; JOHNSON; HULSE, 2002; McCARTHY, 1999), o que também foi observado neste estudo. Nesta pesquisa, a maior porcentagem de lesão iatrogênica de cartilagem ocorreu com o uso de bisturi de radiofreqüência (62,5\%). Acredita-se que tal fato se deva à dimensão relativamente grande deste instrumento para a articulação em estudo. Cabe salientar que HOLSWORTH et al. (2002) utilizaram microbisturi de radiofreqüência em seu estudo, talvez mais apropriado para a espécie e articulação em questão.

Segundo BEALE et al (2003), pode haver quebra de instrumento no interior da articulação durante o procedimento artroscópico. Neste estudo, houve a quebra de lâmina de bisturi $\mathrm{n}$ ㅇ 15 durante a secção proximal do TMBB. A hiperplasia dos vilos sinoviais presente junto ao tubérculo supraglenoidal dificultou a visibilização da transição entre este e o tendão. A prévia remoção destes vilos com shaver permitiria melhor identificação do local de transição.

A produção de bolhas, concomitantemente ao uso do bisturi de radiofrequiência observado neste estudo, não foi citada pelos autores pesquisados (HOLSWORTH et al., 2002; WALL \& TAYLOR 2002). Tal fato dificultou, porém não comprometeu a realização do objetivo proposto, nem os resultados obtidos com o instrumento.

Nesta pesquisa, ocorreu dificuldade comum a todos os instrumentos de corte, não descrita anteriormente, que consistiu na secção de estrutura semelhante a uma plica, que une a cápsula articular cranial com a bainha do TMBB (Figura 3).

\section{CONCLUSÕES}

Concluiu-se que os portais lateral e caudal, para o artroscópio, e lateral e cranial, para o instrumental, são satisfatórios quando a lâmina de a bisturi $\mathrm{n}$ ำ 15 ou o bisturi de radiofreqüência são utilizados para a secção proximal do tendão do músculo bíceps braquial. $\mathrm{O}$ bisturi de radiofreqüência e o bisturi de lâmina nº 15 são superiores à agulha hipodérmica para a secção do TMBB. A hiperplasia de sinóvia presente junto ao tubérculo supraglenoidal pode dificultar a individualização da porção proximal do TMBB, levando a complicações como a quebra da lâmina de bisturi no interior da articulação.

\section{AGRADECIMENTOS}

Os autores agradecem o apoio da Fundação de Amparo e Pesquisa do Estado de São Paulo (FAPESP).

\section{FONTES DE AQUISIÇÃO}

a Karl Storz GmbH \& Co.

b Vídeo Printer - Sony.

c Filmadora - Sony.

d Excalibur Plus PC ${ }^{\circledR}$ - Bisturi eletrocirúrgico - ConMed. Corporation

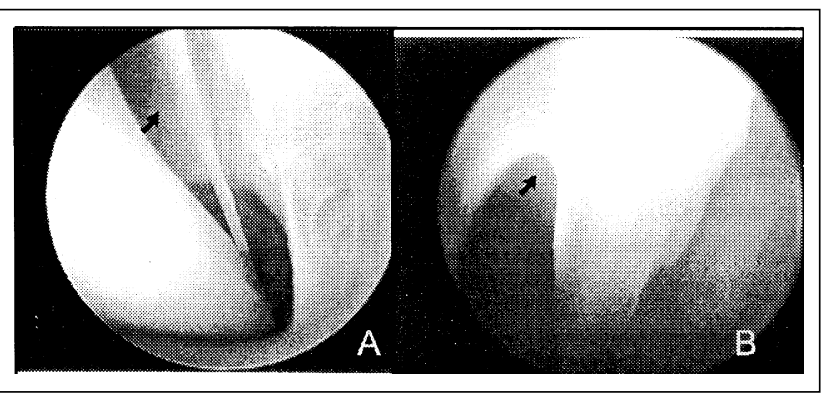

Figura 3 - Articulação escápulo-umeral em cadáver de cão. Em A, observa-se região da bainha do TMBB, com uma plica $(\boldsymbol{\pi})$, que se une à cápsula articular. Em $\mathrm{B}$, maior detalhe da plica ( $)$ observada em A

Ciência Rural, v.36, n.6, nov-dez, 2006. 


\section{REFERÊNCIAS}

BARDET, JF. Lesions of the biceps tendon diagnosis and classification. Vet Comp Orthop Traum, v.12, n.4, p.188195, 1999.

BARDET, J.F. Shoulder diseases in dogs. Vet Med, v.97, n.12, p.909-918, 2002.

BARTHEZ, PY; MORGAN, JP. Bicipital tenosynovitis in the dog - evaluation with positive contrast arthrography. Vet Rad Ultras, v.34, n.5, p.325-330, 1993.

BEALE, B.S. et al. Small animal arthroscopy. Philadelphia: Saunders, 2003. 229p.

GORING, R.L. et al. Medial displacement of the tendon of origin of the biceps brachii muscle in the racing greyhound. $\mathbf{J}$ Am Anim Hosp Assoc, v.20, n.6, p.933-938, 1984.

HOLSWORTH, I.G. et al. Cadaveric evaluation of canine arthroscopic bicipital tenotomy. Vet Comp Orthop Traumatol, v.15, n.4, p.215-222, 2002.

INNES, J.F.; BROWN, G. Ruptures of the biceps brachii tendon sheath in two dogs. J Sm An Pract, v.45, n.1, p.25-28, 2004.

JOHNSON, A.L.; HULSE, D.A. Diseases of the joints. In: FOSSUM, T.W. Small animal surgery. 2.ed. St. Louis: Mosby, 2002. p.883-993.

KRAMER, M. et al. Ultrasonography for the diagnosis of diseases of the tendon and tendon sheath of the biceps brachii muscle. Vet Surg, v.30, n.3, p.64-71, 2001.

LAHUE, T. et al. Entrapment of joint mice in the bicipital5 tendon sheath as a sequela to osteochondritis dissecans of the proximal humerus in dogs. A report of six cases. J Am Anim Hosp Assoc, v.24, n.2, p.99-105, 1986.

LINCOLN, J.D.; POTTER, K. Tenosynovitis of the biceps brachii tendon in dogs. J Am Anim Hosp Assoc, v.20, n.3, p.385-392, 1984.
MCCARTHY, T.C. Arthroscopy. In: FREEMAN, L.J. Veterinary endosurgery. Philadelphia: Mosby, 1999. p.237-250.

MARTINI, F.M. et al. Simplified technique for diagnostic and surgical arthroscopy of the shoulder joint in the dog. J Sm Anim Pract, v.43, n.1, p.7-11, 2002.

MUIR, P. et al. Calcifying tendinopathy of the biceps brachi in a dog. J Am Vet Med Assoc, v.201, n.11, p.1747-1749, 1992.

MUIR, P.; JOHNSON, K.A. Supraspinatus and biceps brachii tendinopathy in dogs. J Sm Anim Pract. v.35, n.5, p.239243, 1994.

PERSON, M.W. Arthroscopy of the canine shoulder joint. Comp Cont Ed Pract Vet, v.8, n.8, p.537-548, 1986

PIERMATTEI, D.L.; FLO, G.L. The shoulder joint. In: Brinker, Piermattei, and Flo's handbook of small animal orthopedics and fracture repair. 3.ed. Philadelphia: Saunders, 1997. p.228-260

RIVERS, B. et al. Biceps tenosynovitis in the dog: radiographic and sonographic findings. Vet Comp Orthop Traum, v.5, n.2, p.51-57, 1992 .

STOBIE, D. et al. Chronic bicipital5 tenosynovitis in dogs: 29 cases (1985-1992). J Am Vet Med Assoc, v.207, n.2, p.201207, 1995.

VAN RYSSEN, B. et al. Small animal arthroscopy. In: SLATTER, D. Textbook of small animal surgery. 3.ed. Philadelphia: Saunders, 2003. p.2285-2312.

VAN RYSSEN, B. et al. Arthroscopy of the shoulder joint in the dog. J Am Anim Hosp Assoc, v.29, n.2, p.101-105, 1993.

WALL; C.R.; TAYLOR; R. Arthroscopic biceps brachii tenotomy as a treatment for canine bicipital tenosynovitis. J Am Anim Hosp Assoc, v.38, n.2, p.169-175, 2002. 